\title{
Postoperative urinary retention
} after pelvic organ prolapse surgery: influence of peri-operative factors and trial of void protocol

\author{
B. C. Anglim *, K. Ramage, E. Sandwith, E. A. Brennand and for the Calgary Women's Pelvic Health Research \\ Group
}

\begin{abstract}
Purpose: Transient postoperative urinary retention (POUR) is common after pelvic floor surgery. We aimed to determine the association between peri-operative variables and POUR and to determine the number of voids required for post-void residuals (PVRs) to normalize postoperatively.

Methods: We conducted a retrospective cohort study of 992 patients undergoing pelvic floor surgery at a tertiary referral centre from January 2015 to October 2017. Variables assessed included: age, BMI, ASA score, anaesthesia type, type of surgery, length of postoperative stay, surgeon, bladder protocol used, and number of PVRs required to "pass" the protocol.

Results: Significant risk factors for POUR included: placement of MUS during POP surgery, anterior repair and hysterectomy with concomitant sacrospinous vault suspension. A total of $25.1 \%$ were discharged requiring catheterization. Patients receiving a concomitant mid-urethral sling (MUS) were $2.2(95 \% \mathrm{Cl} 1.6-2.9)$ and $2.3(95 \% \mathrm{Cl} 1.8-3.1)$ times more likely to have elevated PVR after their second TOV and third TOV $(p<0.0001)$, respectively, compared with those without concomitant MUS. Permitting a third TOV allowed an additional $10 \%$ of women to pass the voiding protocol before discharge. The median number of voids to pass protocol was 2. An ASA $>2$ and placement of MUS were associated with increasing number of voids needed to pass protocol.
\end{abstract}

Conclusions: While many women passed protocol by the second void, using the 3rd void as a cut point to determine success would result in fewer women requiring catheterization after discharge. Prior to pelvic floor surgery, women should be counselled regarding POUR probability to allow for management of postoperative expectations.

Keywords: Voiding dysfunction, Urinary retention, Postoperative voiding trial, Postoperative urinary retention

\section{Introduction}

Transient postoperative urinary retention (POUR) is common following pelvic floor surgery surgery and

*Correspondence: breffini.anglim@gmail.com

Section of Female Pelvic Medicine and Reconstructive Surgery,

Department of Obstetrics and Gynaeacology, Foothills Medical Centre,

School of Medicine, University of Calgary, 140329 Street Northwest,

Calgary, AB T2N 2T9, Canada occurs in $15-45 \%$ of women [1-3]. When POUR is not identified, it can lead to significant morbidity including prolonged bladder distension with associated detrusor injury, renal dysfunction secondary to ureteric reflux and urinary tract infections [4-6]. Undiagnosed POUR may also lead to distressing, emergency presentations to the emergency department for catherization after post-operative discharge. 
Women are at higher risk of POUR following pelvic floor reconstructive surgery. This is likely due to tissue edema, changes in the urethrovesical junction and haematoma formation [7]. Small peripheral nerve endings required for bladder sensation can become temporarily disrupted, resulting in a transient neuropathy and resultant bladder dysfunction [4]. Previously evaluated risk factors for POUR include: lower body mass index (BMI), advanced age, higher stage of prolapse, anterior colporrhaphy, previous incontinence surgery, and high preoperative post void residuals (PVR) [8-12]. Intravenous fluid administration of $>750 \mathrm{~mL}$ or a bladder volume of $\geq 270 \mathrm{~mL}$ in the postanaesthetic recovery area has also been shown to increase the risk of POUR [13]. In addition to this, increased opioid administration is associated with a 1.5 times higher risk of developing POUR (OR 1.3) [14]. Interestingly, a study by Bracken et al. [15] showed that vaginal bupivacaine used at the time of midurethral sling (MUS) placement increased the rate of POUR but did not reduce pain levels or pain medication use [15].

The optimal mode of bladder filling prior to postoperative trial of void (TOV) is unknown. Two main methods of trial of void exist: (1) retrograde filling the bladder using the foley catheter left in situ, and (2) spontaneous bladder filling (16-20). Retrograde voiding trials have a sensitivity of $94.4 \%$ and a specificity of $58.1 \%$ in detection of urinary retention [16]. Spontaneous fill has a sensitivity of $100 \%$ and specificity of $25.8 \%$; however, this method may take longer to complete than the retrograde approach due to the time needed for the bladder to naturally and passively fill [16]. A study by Pulvino et al. [17] compared retrograde fill of $300 \mathrm{ml}$ using a foley catheter and spontaneous fill to determine TOV success. The retrograde fill technique resulted in statistically significantly more complete bladder emptying compared to the spontaneous fill. It also showed less heterogeneity in bladder volume during the TOV and less overdistension to bladder volumes over $450 \mathrm{ml}$ [17]. Another study by Dolgun et al. [18] showed TOV success to be equal between spontaneous fill and retrograde groups. The spontaneous void group required women to void $\geq 150 \mathrm{ml}$ to pass, compared to the retrograde fill group who had more stringent criteria and were required to void $200 \mathrm{ml}$ and have a PVR $<100 \mathrm{ml}$. A similar percentage of women in both groups returned with urinary retention requiring catheter insertion [18].

POUR is a common occurrence following pelvic floor surgery and can lead to significant anxiety and distress if women are discharged with a catheter or self-catheterizing. The primary aim of this study was to determine which peri-operative factors were associated with developing POUR. This information was felt to be valuable for pre-operative patient counselling regarding expectations for postoperative catheterization. Our secondary aim was to determine the average number of voids required for post void residuals (PVRs) to normalize postoperatively.

\section{Materials and methods}

We conducted a retrospective cohort study of patients who underwent pelvic floor reconstructive surgery with four surgeons at a tertiary referral centre from January 2015 to October 2017. This project was reviewed and approved by the Foothills Medical Centre Research Ethics Boards (IDs\# CHREB150706). Surgeries included for analysis were obliterative procedures (with or without MUS) and reconstructive procedures that addressed the vaginal apex (including vaginal hysterectomy with sacrospinous or uterosacral vault suspension, with or without anterior and posterior colporrhaphy, sacrospinous vault suspension, sacrocolpopexy (SCP), with or without MUS). Cases were identified in the Section of Pelvic Medicine \& Reconstructive Surgery Surgical Booking Database. Peri-operative data was entered as part of routine clinical practice in the city-wide inpatient EMR (Sunrise Clinical Manager) and abstracted by a FPMRS/ Urogynecology fellow to a database designed for research purposes.

Single site prolapse surgeries such as isolated anterior or posterior repairs were not captured by the dataset. All MUS procedures at time of pelvic organ prolapse (POP) surgery were performed with the use of vaginal xylocaine $1 \%$ with 1:100,000 Epinephrine mixed 1:1 with sterile water, in the range of 10-40 $\mathrm{ml}$ for hydro dissection during placement. Patients were excluded from our study if they underwent hysterectomies that did not include an apical suspension procedure (such as those performed for non-prolapse indications), isolated incontinence surgeries, vesicovaginal and rectovaginal fistula repairs, as well as day surgery cases (such as dilation \& curettage, laparoscopic resection of endometriosis). Patients who had pre-operatively elevated post-void residuals $\geq 150 \mathrm{ml}$ were excluded from this dataset. Data were extracted from the patient's post-operative electronic chart. Variables extracted included: age, body mass index (BMI), American Society of Anesthesiologists (ASA) score as a marker of health, previous pelvic floor surgery and type of procedure performed. Perioperative variables extracted included: length of hospital stay (in days), number of voiding trials in hospital and whether the patient was sent home with a catheter or self-catheterizing.

At the tertiary centre where the study was conducted, two bladder protocols are administered in the post-operative period at the attending surgeon's discretion. The first (Retrograde Protocol) is carried out by retro-filling the bladder with $300 \mathrm{ml}$ of normal saline or sterile water 
through the foley catheter which was left in situ overnight. The voided volume is measured in a voiding hat by nurses and post void residual (PVR) is determined based on the volume voided. The second and subsequent (Spontaneous Filling Protocol) bladder protocols involve removing the foley catheter and allowing the bladder to spontaneous fill. The patient must void within $4 \mathrm{~h}$ of catheter removal, and PVR is measured by bedside bladder scanner. Voided volumes are measured in a voiding hat by nurses and the PVR measured with a bladder scanner. If patients have two consecutive voids $>200 \mathrm{ml}$ with a PVR $\leq 150 \mathrm{ml}$, then they are considered to have passed the bladder protocol and monitoring of voiding stops. If the first TOV is failed, then two further consecutive voids must be "passed" in order to pass the voiding protocol. If the PVR is $>250 \mathrm{ml}$, an in \& out catheter is placed to both confirm PVR and decompress the bladder. With both of these protocols, the post-operative indwelling catheter is removed at 6 AM on Day 1 in compliance with Early Recovery After Surgery (ERAS) guidelines for minimal duration of catheterization [19]. Patients must pass a minimum of two consecutive TOVs in order to pass the voiding protocol. This is based on the unreliability of PVR measurements a the need for repetition to confirm consistency [20]. A study by Dunsmuir et. al., showed that only one-third of patients had approximately constant PVRs (variation in range $<120 \mathrm{~mL}$ ), and so repeated transabdominal bladder ultrasound is required [21]. A patient may have a falsely low PVR and may represent with urinary retention if only one PVR is done as part of a TOV. Type of bladder protocol administered and results are then documented in the electronic patient chart.

If the patient has met all other criteria for discharge, but have not passed their TOV, they are given the option to perform self-catheterization after each measured void at home or to be discharged with an indwelling foley catheter. Those patients who elect to self-catheterize upon discharge can discontinue self- catheterization once their voiding pattern demonstrates voids of $>200 \mathrm{ml}$ with a PVR $\leq 150 \mathrm{ml}$ for 3 consecutive voids. Those who elect to discharge with a catheter are reviewed in clinic for a retrograde TOV performed 4-7 days after discharge. This is in keeping with a prospective randomized controlled trial by Schachar et al. which showed that women with POUR after prolapse surgery had a sevenfold higher risk of failed repeat office TOV if performed on postoperative day 4 compared to postoperative day 7 [22].

Statistics were conducted using Stata 16 (College Station, Texas). Descriptive statistics were used to describe the study sample, calculating proportions, mean, and median values for demographic characteristics. Elevated PVR was defined as having a PVR of greater than 150 cc. We calculated descriptive statistics, chi-square tests, and crude odds ratios for elevated PVR on the second void, stratifying the results by POP procedure type (reconstructive vs. obliterative) and presence of MUS procedure. Reconstructive procedures were then further stratified by concomitant versus previous hysterectomy to explore for effect of hysterectomy on POUR risk factors.

Sample size for regression-based analyses is difficult to compute a-priori. However, a general rule of 10 cases/ events per regression variable is accepted for logistic regression. Our original model included over 10 variables and multiple interaction terms. For this reason, we estimated we would need 200 events for our logistic regression model. Recognizing that some cases may have missing information due to charting errors, we increased our sample size by $20 \%$ to 240 events. Estimating the prevalence of post-operative urinary retention to be $40 \%$ this would be a sample size of 600 women. However, recognizing that other forms of regression analysis would require samples larger than logistic regression due to multiple group comparisons, the same size was again increased by $50 \%$ to 900 . Based on our average surgical volume, it was estimated that a review of all cases over 34 months would provide this volume (January 2015-October 2017).

We conducted several regression analyses, recognizing that the concept of POUR can be defined multiple ways. Binary logistic regression evaluated for the effect of patient age, BMI, ASA Score, bladder protocol type, anesthesia type (general vs regional), surgeon, concomitant hysterectomy, anterior and posterior vaginal wall repairs on the outcome of passing the TOV at the second post-operative void. Age and BMI were explored in linear and non-linear fashion. Interaction terms between age and BMI and combinations of surgical procedures were explored. We also explored the potential effect of surgeon on the voiding outcomes through mixed effects logistic regression and the value of the variance reported by McFadden's R-squared (not reported).

Association with the absolute number of voids taken to pass the bladder protocol and peri-operative variables were explored by zero-truncated Poisson regression where the dependent variable is an observed, non-zero count, assumed to follow a Poisson distribution. The Poisson regression modelling examined whether any measured clinical variable (including age, BMI, MUS, ASA score, anaesthesia type, hysterectomy, uterosacral or sacrospinous suspension, and laparoscopic SCP) predicted the number of voids to pass the bladder protocol. Both crude odds ratios and adjusted odds ratios were calculated.

Plotting a histogram of the number of voids required to pass the TOV allowed us to determine where natural 
clustering of the data occurred, and to classify pattern groups of the number of voids needed to pass the TOV were performed which were ordinal in nature. We assessed the proportional odds assumption using the Brant test. Results of the Brant test indicated that the proportional odds assumption was not violated and that we can assume that the relationship between each pair of outcome groups is the same (i.e., being in class 2 or 3 compared to 1 is the same as being in group 3 compared to 2 and 1). We calculated both crude models (using the single predictor variable and the outcome of void class) and adjusted models (using all predictor variables and the outcome of void class).

For all of the regression modelling, we assessed for significance at the $p<0.05$ level. For the binary outcome of passing TOV on the second void, sensitivity analyses using a cutpoint of a 3rd void was also performed. Use of multiple regression methodologies acted as sensitivity analysis to ensure our results were consistent across different ways of classifying POUR.

\section{Results}

Overall, our study examined the association with procedure and demographic characteristics and POUR for 992 women receiving pelvic floor reconstructive surgery at a tertiary care centre. Demographic characteristics of our study sample are described in Table 1 . A total of $25.1 \%$ were discharged home with an indwelling catheter or performing self-catheterization.

We examined characteristics of women having a PVR $>150 \mathrm{ml}$ by obliterative vs. reconstructive procedures (Table 2). Overall, 51.2\% (95\%CI 48.0-54.3\%) of women in our study had elevated PVR after their second void and 40.8\% (95\%CI 37.7-43.9\%) had elevated PVR after their third void. Overall, those receiving a concomitant MUS procedure were 2.2 (95\% CI 1.6-2.9) times as likely to have elevated PVR after their second TOV $(p<0.0001)$ and $2.3(95 \%$ CI 1.8-3.1) times as likely to have elevated PVR after their third TOV $(p<0.0001)$. Elevated PVR after second and third void significantly differed by the presence of a MUS in reconstructive procedures, however, odds of elevated PVR were not significantly different by the presence of a concomitant MUS procedure for obliterative procedures, likely due to the relatively small sample size of women receiving both obliterative and MUS surgery. For obliterative procedures, no variable was associated with the odds of failing the bladder protocol, making pre-operative prediction of outcomes difficult in this group.

We also examined the characteristics of women having a PVR $>150 \mathrm{ml}$ by hysterectomy status, comparing those who had undergone previous hysterectomy and thus only had a vault suspension performed vs. those undergoing hysterectomy and concomitant apical suspension procedures. This stratification is shown in Table 3.

In the reconstructive group without concomitant hysterectomy, logistic regression was used to examine the outcome of failing the bladder protocol after 2nd and 3rd TOV. Performance of a concomitant MUS was associated with odds of failing the bladder protocol on the 2nd TOV (aOR 3.08, 95\%CI 1.67-5.68) and the 3rd TOV (aOR 2.96, 95\%CI 1.65-5.33). Adjusted odds ratios (aORs) of failing the TOV after sacrospinous vault suspension and laparoscopic SCP in the absence of a hysterectomy were not significant (aOR 1.18, 95\% CI 0.71-1.97 and aOR 1.02, 95\%CI 0.621-1.69, respectively), nor was the crude OR comparing the two after 2nd and 3rd TOV, as shown in Table 3. For reconstructive procedures with a concomitant hysterectomy, MUS and anterior repair were significant predictors of failing the bladder protocol after the 2nd and 3rd TOV. When adjusting for MUS status and anterior repair, the adjusted odds ratios for sacrospinous vault suspension compared to uterosacral vault suspension were not significant (aOR 1.10, 95\% CI 0.70-1.72 and aOR $0.87,95 \% \mathrm{CI} 0.56-1.36$, respectively), nor were the crude ORs shown in Table 3.

In our crude logistic regression modelling, the OR of the Retrograde fill TOV compared to the spontaneous fill TOV was significant, with Retrograde TOV being 1.35 times (95\%CI 1.04-1.75) as likely as natural fill TOV to fail the 2 nd void and 1.45 times (95\%CI 1.12-1.89) as likely to fail the 3rd void. However, in the adjusted model, these values were not significant for the 2 nd void (aOR 1.16 , 95\%CI $0.89-1.52$ ) or 3 rd void (aOR 1.23, 95\% CI 0.94-1.62), indicating that type of TOV does not influence the odds of passing the TOV on 2nd and 3rd TOV. The incidence rate ratio of this variable (comparing retrograde to spontaneous fill) in the adjusted zero-truncated Poisson regression model was 1.01 (95\%CI 0.70-1.46), again suggesting it does not affect the absolute number of voids required to pass. This variable was then removed from the logistic regression modelling.

Three surgical procedures were found to be consistently associated with higher odds of having a PVR $>150 \mathrm{ml}$ on the 2 nd and 3rd postoperative voids (results not shown in table). These were: (1) performance of concomitant MUS procedure (after 2nd void: adjusted OR 2.22, 95\%CI $1.62-$ 3.05 ; and after 3rd void: adjusted OR 2.27; 95\%CI 1.67$3.08)$; (2) anterior repair (after 2nd void: adjusted OR 1.55, 95\%CI 1.18-2.06; and after 3rd void: adjusted OR $1.49,95 \%$ CI 1.12-1.99); and (3) performance of hysterectomy (after 2nd void, adjusted OR 1.56, 95\%CI 1.18-2.05 and after 3rd void, adjusted OR 1.71, 95\%CI 1.29-2.25). Elevated BMI was found to be associated with declining odds of failing bladder protocol on 3rd TOV (adjusted OR 0.97, 95\%CI 0.95-0.99), but not the 2nd TOV. 
Table 1 Demographic characteristics of women undergoing pelvic floor reconstructive surgery from Jan 2015 to October 2017 $(n=992)$

\begin{tabular}{|c|c|c|c|}
\hline & Median (IQR) & $\begin{array}{l}\text { Mean } \\
95 \% \mathrm{Cl}\end{array}$ & \\
\hline Age (years) & $\begin{array}{l}62 \\
\text { IQR: 53-71 }\end{array}$ & $\begin{array}{l}61.5 \\
95 \% \mathrm{Cl} 60.7-62.3\end{array}$ & \\
\hline BMI & $\begin{array}{l}27.4 \\
\text { IQR: } 24.3-31.2\end{array}$ & $\begin{array}{l}28.4 \\
95 \% \mathrm{Cl} 28.0-28.7\end{array}$ & \\
\hline Length of stay (days) & $\begin{array}{l}1 \\
\text { IQR: } 1-2\end{array}$ & $\begin{array}{l}2.0 \\
95 \% \text { Cl } 1.3-2.7\end{array}$ & \\
\hline \multirow[t]{2}{*}{ Number of voids to pass bladder protocol } & $\begin{array}{l}2 \\
\text { IQR: 2-3 }\end{array}$ & $\begin{array}{l}3.0 \\
95 \% \mathrm{Cl} 2.9-3.2\end{array}$ & \\
\hline & & $\mathrm{N}$ & $\begin{array}{l}\text { Proportion (\%) } \\
95 \% \mathrm{Cl}\end{array}$ \\
\hline \multirow[t]{4}{*}{ ASA score (\%) } & 1 & 420 & $\begin{array}{l}42.5 \% \\
95 \% \mathrm{Cl} 39.4-45.6 \%\end{array}$ \\
\hline & 2 & 505 & $\begin{array}{l}51.1 \% \\
95 \% \mathrm{Cl} 47.9-54.2 \%\end{array}$ \\
\hline & 3 & 63 & $\begin{array}{l}6.4 \% \\
95 \% \mathrm{Cl} 5.0-8.1 \%\end{array}$ \\
\hline & 4 & 1 & $\begin{array}{l}0.1 \% \\
95 \% \text { Cl } 0.01-0.7 \%\end{array}$ \\
\hline \multirow[t]{2}{*}{ Anaesthesia type } & Regional & 89 & $\begin{array}{l}9.0 \% \\
95 \% \text { Cl } 7.4-10.9 \%\end{array}$ \\
\hline & General & 902 & $\begin{array}{l}91.0 \% \\
95 \% \mathrm{Cl} 89.1-92.6 \%\end{array}$ \\
\hline \multirow[t]{10}{*}{ Surgery type } & Colpocleisis & 51 & $\begin{array}{l}5.1 \% \\
95 \% \mathrm{Cl} 3.9-6.7 \%\end{array}$ \\
\hline & Sacrospinous Suspension & 380 & $\begin{array}{l}38.3 \% \\
95 \% \mathrm{Cl} 35.3-41.4 \%\end{array}$ \\
\hline & Uterosacral Suspension & 261 & $\begin{array}{l}26.3 \% \\
95 \% \text { Cl } 23.7-29.1 \%\end{array}$ \\
\hline & Anterior Repair & 587 & $\begin{array}{l}59.2 \% \\
95 \% \text { Cl } 56.1-62.2 \%\end{array}$ \\
\hline & Posterior Repair & 715 & $\begin{array}{l}72.1 \% \\
95 \% \mathrm{Cl} 69.2-74.8 \%\end{array}$ \\
\hline & Lap SCP & 107 & $\begin{array}{l}10.8 \% \\
95 \% \text { Cl } 9.0-12.9 \%\end{array}$ \\
\hline & TVT & 150 & $\begin{array}{l}15.1 \% \\
95 \% \mathrm{Cl} 13.0-17.5 \%\end{array}$ \\
\hline & TOT & 85 & $\begin{array}{l}8.6 \% \\
95 \% \text { Cl } 7.0-10.5 \%\end{array}$ \\
\hline & MUS & 235 & $\begin{array}{l}23.7 \% \\
95 \% \text { Cl } 21.1-26.4 \%\end{array}$ \\
\hline & Vaginal hysterectomy & 382 & $\begin{array}{l}38.5 \% \\
95 \% \mathrm{Cl} 35.5-41.6 \%\end{array}$ \\
\hline \multirow[t]{2}{*}{ Type of bladder protocol } & Spontaneous filling & 399 & $\begin{array}{l}41.3 \\
95 \% \text { Cl } 38.2-44.4 \%\end{array}$ \\
\hline & Retrograde filling & 568 & $\begin{array}{l}58.7 \% \\
95 \% \text { Cl } 55.6-61.8 \%\end{array}$ \\
\hline \multirow[t]{3}{*}{ Voids to pass categories } & $1-3$ & 573 & $\begin{array}{l}75.1 \% \\
95 \% \text { Cl } 71.9-78.0 \%\end{array}$ \\
\hline & $4-8$ & 130 & $\begin{array}{l}17.0 \% \\
95 \% \text { Cl 14.5-19.9\% }\end{array}$ \\
\hline & 9 or more & 60 & $\begin{array}{l}7.9 \% \\
95 \% \mathrm{Cl} 6.2-10.0 \%\end{array}$ \\
\hline Patients electing discharge with catheter & 249 & $\begin{array}{l}25.1 \% \\
95 \% \mathrm{Cl} 22.5-27.9 \%\end{array}$ & \\
\hline
\end{tabular}


Table 1 (continued)

* Some numbers may not add up to $100 \%$ due to missing data

The findings of the mixed effects logistic regression indicated that the surgeon variable explained only $3.9 \%$ of the variance in the model predicting elevated PVR at the 2nd void and $7.5 \%$ of the variance in the model predicting elevated PVR at the 3rd void. This suggests the individual differences in each surgeon's technique does not influence the outcome of POUR greatly.

In the adjusted Poisson regression model, we found that the presence of a MUS and having an ASA score of two or higher significantly increased the number of voids until the protocol was passed by 1.27 (95\%CI 1.13-1.42) and 1.15 times (95\%CI 1.03-1.27), respectively. Finally, although undergoing a vaginal hysterectomy or a sacrospinous suspension separately were not significantly associated with an increase in the number of voids until the bladder protocol was passed, having both a vaginal hysterectomy and sacrospinous suspension significantly increased the number of voids by 1.53 times $(95 \% \mathrm{CI}$ $1.18-1.97)$. Other predictors were not significantly associated with the number of voids until the protocol was passed (Table 4).

Using visual inspection of the data, we defined patterns of voids after surgery using natural breaks in the number of void passes after surgery. This defined three clusters patients requiring $1-3$ voids, $4-8$ voids, or $>8$ voids to pass the protocol. Using ordinal regression (Table 5), we found that MUS, ASA score, and having a hysterectomy with sacrospinous suspension were significant predictors of void class. If a MUS was performed, the adjusted odds of taking longer (going up a void class) to void are 2.27 times higher (95\%CI 1.52-3.40) assuming all other factors to be constant in the model. Having an ASA score of 2 or higher increased the odds of taking longer to void by 1.47 times (95\% CI 1.01-2.14).

\section{Discussion}

This rigorous analysis of POUR following pelvic floor reconstructive surgery provides valuable information for clinicians which can help counsel women preoperatively and manage their postoperative expectations where postoperative catheterization may be required. In our analysis of all pelvic floor procedures, $51.2 \%$ passed the TOV after the 3 rd TOV compared to $40.8 \%$ after the 2 nd TOV, equating to an extra $10.4 \%$ passing the TOV and not requiring catheterization if a 3rd TOV was performed. This difference was similar when accounting for surgery with or without MUS.

Previous studies have shown that lower BMI, older women and anterior colporrhaphy are associated with higher risk of POUR [8-12]. In our analysis we found only modest differences in the reconstructive vs. obliterative approaches. This difference was primarily driven by reconstructive surgery with a hysterectomy. In the regression modelling, which includes all cases and thus does not lose power like a stratification approach, the effect of hysterectomy was only in the presence of a concomitant sacrospinous suspension. This may be due to longer operation times, higher intraoperative blood loss [3] or perhaps irritation to the pudendal nerves in the region of the sacrospinous suspension [23]. Interestingly, age and BMI were not strongly predictive in the regression models we used. In the truncated Poisson and ordinal regression models, an ASA score greater than 2 (a marker for medical co-morbidities) was associated with increasing number of voids needed to pass protocol. This suggests that rather than parameters such as age and BMI impacting ability to void after surgery, it is a woman's overall level of health that is associated with POUR. We also did not find that a woman's attending surgeon was predictive of the risk of experiencing POUR. The small variance contributed to the model by differing surgeons reassures that these associations are common to all four surgeons and not influenced by individual differences in technique.

In our study, placement of MUS was consistently the most significant risk factor for POUR. This is likely due to the fact that incontinence surgery aims to correct urethral hypermobility and are inherently designed to cause some degree of urethral obstruction [4]. Women who are fearful or unable to deal with elevated residuals after surgery (such as those experiencing issues with dexterity, obesity, or anxiety) may want to consider staging their incontinence procedure after POP procedure as concomitant sling at the time of POP surgery increased the risk of POUR [24].

Rates of failure of 2nd and 3rd TOVs are very high at our institution ranging from $36.1 \%$ (for POP procedures without MUS) to $56.2 \%$ (for POP procedures with MUS) after the 3rd TOV. This may be due to the early removal of catheter at 6am in keeping with ERAS guidelines. This would be in keeping with prior studies that suggest higher rates of successful TOV with longer catherization [25]. While early catheter removal is compliant with ERAS guidelines, it may result in significant proportions of women requiring intermittent catheterization for POUR and resultant increased UTIs. The possibility of being discharged home with an indwelling catheter or self-catheterizing can trigger anxiety and may also 


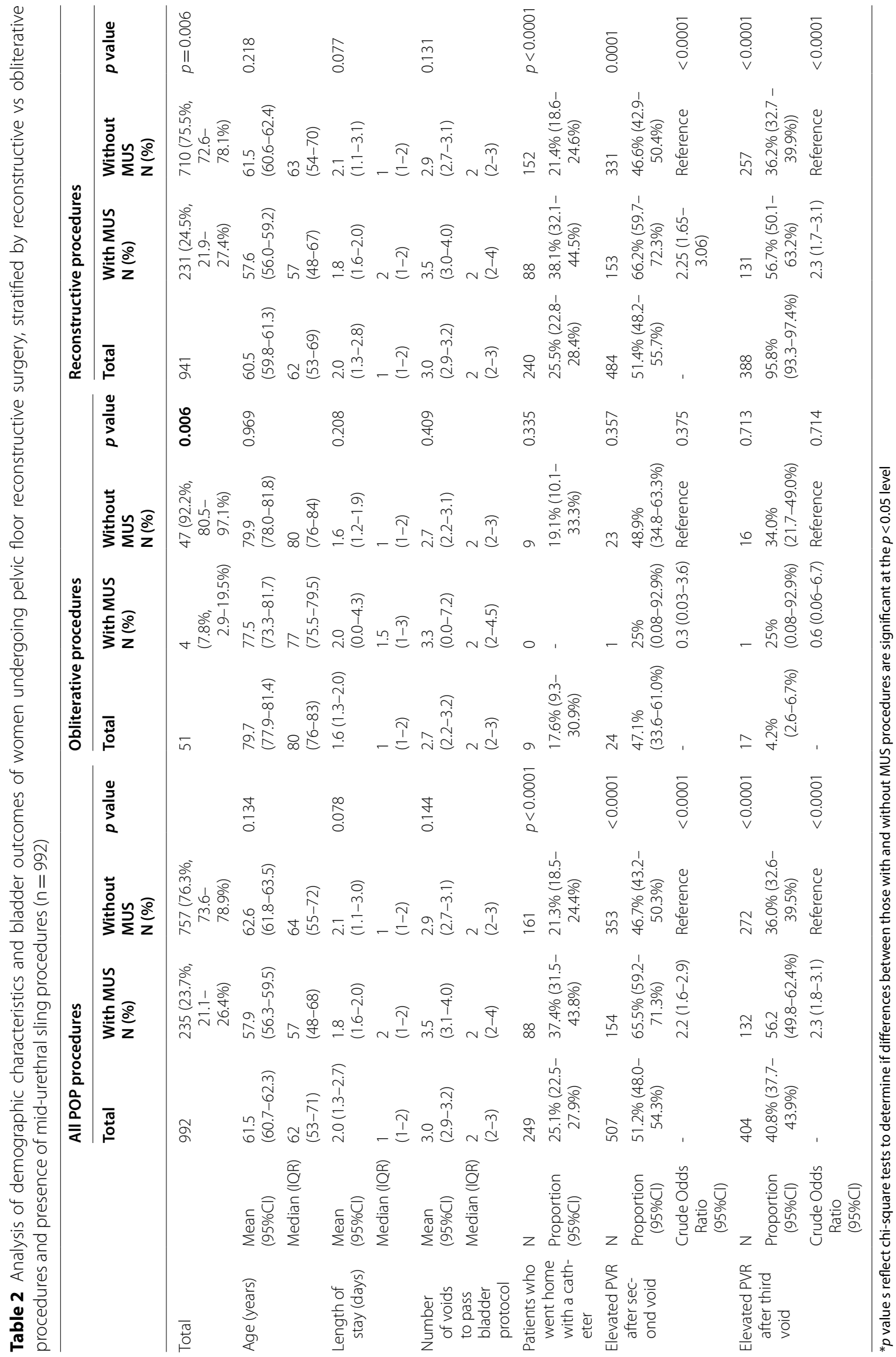


Table 3 Analysis of demographic characteristics and bladder outcomes of women undergoing pelvic floor reconstructive surgery, stratified by hysterectomy status

\begin{tabular}{|c|c|c|c|c|c|c|c|c|c|}
\hline & & \multicolumn{4}{|c|}{ Reconstructive surgery with previous hysterectomy } & \multicolumn{4}{|c|}{$\begin{array}{l}\text { Reconstructive surgery with concomitant } \\
\text { hysterectomy }\end{array}$} \\
\hline & & Total & Sacrocolpopexy & $\begin{array}{l}\text { Sacrospinous } \\
\text { suspension }\end{array}$ & $p$ value & Total & $\begin{array}{l}\text { Uterosacral } \\
\text { suspension }\end{array}$ & $\begin{array}{l}\text { Sacrospinous } \\
\text { suspension }\end{array}$ & $p$ value \\
\hline Total & & 308 & $\begin{array}{l}105 \\
(34.1 \%, 29.0- \\
39.6 \%)\end{array}$ & $\begin{array}{l}203 \\
(65.9 \% \\
\quad 60.4-71.0 \%)\end{array}$ & & 364 & $\begin{array}{l}228 \\
(62.6 \%, 57.5- \\
67.5 \%)\end{array}$ & $\begin{array}{l}136 \\
(37.4 \% \\
32.5-42.5 \%)\end{array}$ & \\
\hline \multirow[t]{2}{*}{ Age (years) } & $\begin{array}{l}\text { Mean } \\
(95 \% \mathrm{Cl})\end{array}$ & $\begin{array}{l}64.5 \\
(63.3-65.7)\end{array}$ & $\begin{array}{l}63.5 \\
(61.8-65.3)\end{array}$ & $\begin{array}{l}65.0 \\
(63.5-66.6)\end{array}$ & 0.377 & $\begin{array}{l}60.2 \\
(59.1-61.4)\end{array}$ & $\begin{array}{l}59.4 \\
(57.9-60.9)\end{array}$ & $\begin{array}{l}61.5 \\
(59.9-63.2)\end{array}$ & 0.254 \\
\hline & Median (IQR) & $\begin{array}{l}65 \\
(57.5-72)\end{array}$ & $\begin{array}{l}63 \\
(57-71)\end{array}$ & $\begin{array}{l}66 \\
(58-73)\end{array}$ & & $\begin{array}{l}62 \\
(53-69)\end{array}$ & $\begin{array}{l}61 \\
(51-68)\end{array}$ & $\begin{array}{l}62 \\
(55-69)\end{array}$ & \\
\hline \multirow[t]{2}{*}{$\begin{array}{l}\text { Length of stay } \\
\text { (days) }\end{array}$} & $\begin{array}{l}\text { Mean } \\
(95 \% \mathrm{Cl})\end{array}$ & $\begin{array}{l}2.8 \\
(0.5-5.1)\end{array}$ & $\begin{array}{l}1.8 \\
(1.4-2.1)\end{array}$ & $\begin{array}{l}3.3 \\
(0.0-6.9)\end{array}$ & 0.622 & $\begin{array}{l}1.8 \\
(1.6-2.0)\end{array}$ & $\begin{array}{l}1.7 \\
(1.5-1.9)\end{array}$ & $\begin{array}{l}1.8 \\
(1.6-2.1)\end{array}$ & 0.524 \\
\hline & Median (IQR) & $(1-2)$ & $(1-2)$ & $(1-2)$ & & $\begin{array}{l}2 \\
(1-2)\end{array}$ & $(1-2)$ & $(1-2)$ & \\
\hline \multirow{2}{*}{$\begin{array}{l}\text { Number } \\
\text { of voids } \\
\text { to pass } \\
\text { bladder } \\
\text { protocol }\end{array}$} & $\begin{array}{l}\text { Mean } \\
(95 \% \mathrm{Cl})\end{array}$ & $\begin{array}{l}2.8 \\
(2.5-3.0)\end{array}$ & $\begin{array}{l}2.7 \\
(2.4-3.0)\end{array}$ & $\begin{array}{l}2.8 \\
(2.4-3.1)\end{array}$ & 0.439 & $\begin{array}{l}3.4 \\
(3.1-3.7)\end{array}$ & $\begin{array}{l}3.4 \\
(3.0-3.9)\end{array}$ & $\begin{array}{l}3.6 \\
(3.1-4.1)\end{array}$ & 0.056 \\
\hline & Median (IQR) & $\begin{array}{l}2 \\
(2-3)\end{array}$ & $\begin{array}{l}2 \\
(2-3)\end{array}$ & $\begin{array}{l}2 \\
(2-3)\end{array}$ & & $\begin{array}{l}2 \\
(2-4)\end{array}$ & $\begin{array}{l}2 \\
(2-4)\end{array}$ & $\begin{array}{l}3 \\
(2-4)\end{array}$ & \\
\hline \multirow{2}{*}{$\begin{array}{l}\text { Patients who } \\
\text { went home } \\
\text { with a } \\
\text { catheter }\end{array}$} & $\mathrm{N}$ & 78 & 23 & 55 & 0.321 & 119 & 79 & 40 & 0.303 \\
\hline & $\begin{array}{l}\text { Proportion } \\
(95 \% \mathrm{Cl})\end{array}$ & $\begin{array}{l}25.3 \%(20.8- \\
30.5 \%)\end{array}$ & $\begin{array}{c}21.9 \%(15.0- \\
30.9 \%)\end{array}$ & $\begin{array}{l}27.1 \%(21.4- \\
33.6 \%)\end{array}$ & & $\begin{array}{l}32.7 \%(28.1- \\
37.7 \%)\end{array}$ & $\begin{array}{c}34.6 \%(28.7- \\
41.1 \%)\end{array}$ & $\begin{array}{l}29.4 \%(22.3- \\
37.7 \%)\end{array}$ & \\
\hline \multirow{3}{*}{$\begin{array}{l}\text { Elevated PVR } \\
\text { after sec- } \\
\text { ond void }\end{array}$} & $\mathrm{N}$ & 146 & 50 & 96 & 0.896 & 223 & 137 & 86 & 0.551 \\
\hline & $\begin{array}{l}\text { Proportion } \\
(95 \% \mathrm{Cl})\end{array}$ & $\begin{array}{l}48.6 \%(42.0- \\
53.2 \%)\end{array}$ & $\begin{array}{l}48.1 \% \\
(38.2-58.1 \%)\end{array}$ & $\begin{array}{l}47.3 \% \\
(40.3-54.4 \%)\end{array}$ & & $\begin{array}{l}61.3 \% \\
(56.1-66.2 \%)\end{array}$ & $\begin{array}{l}60.1 \% \\
(53.4-66.5 \%)\end{array}$ & $\begin{array}{l}63.2 \% \\
(54.5-71.3 \%)\end{array}$ & \\
\hline & $\begin{array}{l}\text { Crude Odds } \\
\text { Ratio } \\
(95 \% \mathrm{Cl})\end{array}$ & - & $\begin{array}{l}1.0 \\
(0.6-1.7)\end{array}$ & Reference & & - & $\begin{array}{l}0.9 \\
(0.6-1.4)\end{array}$ & Reference & \\
\hline \multirow{3}{*}{$\begin{array}{l}\text { Elevated PVR } \\
\text { after third } \\
\text { void }\end{array}$} & $N$ & 116 & 39 & 77 & 0.941 & 189 & 120 & 69 & 0.726 \\
\hline & $\begin{array}{l}\text { Proportion } \\
(95 \% \mathrm{Cl})\end{array}$ & $\begin{array}{l}37.8 \% \\
(32.5-43.4 \%)\end{array}$ & $\begin{array}{l}37.5 \% \\
(28.2-47.5 \%)\end{array}$ & $\begin{array}{l}37.9 \% \\
(31.2-45.0 \%)\end{array}$ & & $\begin{array}{l}51.9 \% \\
(46.8-57.0 \%)\end{array}$ & $\begin{array}{l}52.6 \% \\
(45.9-59.3 \%)\end{array}$ & $\begin{array}{l}50.7 \% \\
(42.0-59.4 \%)\end{array}$ & \\
\hline & $\begin{array}{l}\text { Crude Odds } \\
\text { Ratio } \\
(95 \% \mathrm{Cl})\end{array}$ & - & $\begin{array}{l}0.98 \\
(0.6-1.6)\end{array}$ & Reference & & - & $\begin{array}{l}1.1 \\
(0.7-1.7)\end{array}$ & Reference & \\
\hline
\end{tabular}

The uterosacral suspension group for those with previous hysterectomy and the sacrocolpopexy for those with concomitant hysterectomy were excluded because of small sample size. Some values may not add to $100 \%$ due to missing values

increase the risk of infection, which may impact patient satisfaction with their surgical experience [26]. This is of particular relevance for women who are scheduled for day case surgery and are keen not to be discharged with a catheter or self-catheterizing. Such information should be relayed to the day unit nursing staff and, where resources exist, an extra, third TOV should be attempted. Women at higher risk of POUR based on risk factors previously mentioned may benefit from being placed at the start of the day, thus benefiting from a longer time in PACU for their TOV. Future research could examine the impact of catheterization for POUR and its relationship to women's perception of the surgery experience.

Finally, our study presents normative data on the number of voids required for PVRs to normalize postoperatively. Prior work suggests that on average 2-3 TOV are performed in the postoperative period, either on the ward or in the day care unit/post anesthetic care unit $[15,16]$. Our study found the median number of voids to pass protocol was 2 for both reconstructive and obliterative procedures and the natural patterns of voiding identified in our analysis $(1-3,4-8$, or $>8$ voids to pass TOV) corresponds to the 75 th percentile, 75 th-95th percentile, and greater than the 95 th percentile. This suggests that requiring $>3$ voids to pass a bladder protocol should be the definition of POUR, and that patients requiring 8 or more voids are true outliers. Patients and the nurses who provide post-operative case to them should be taught that it is perfectly normal to require 3 voids for the postvoid residual to normalize. 
Table 4 Results of zero-truncated poisson regression analysis examining the association between clinical variables and number of voids to pass the bladder protocol

\begin{tabular}{|c|c|c|c|c|}
\hline Clinical Variables & $\begin{array}{l}\text { Crude Incidence rate } \\
\text { ratio (RR, } 95 \% \mathrm{Cl} \text { ) }\end{array}$ & $p$ value & $\begin{array}{l}\text { Adjusted Incidence rate } \\
\text { ratio (RR, } 95 \% \mathrm{Cl})\end{array}$ & $p$ value \\
\hline Age & $99.9(99.6-1.00)$ & 0.664 & $99.9(99.5-1.00)$ & 0.984 \\
\hline BMl & $1.00(0.99-1.01)$ & 0.944 & $99.7(98.9-1.01)$ & 0.470 \\
\hline MUS & $1.27(1.14-1.41)$ & $<0.0001$ & $1.27(1.13-1.42)$ & $<0.0001$ \\
\hline ASA score & $1.09(0.995-1.20)$ & 0.062 & $1.15(1.03-1.27)$ & 0.010 \\
\hline Anterior repair & $1.12(1.02-1.23)$ & 0.019 & $1.05(0.92-1.16)$ & 0.451 \\
\hline Posterior repair & $1.08(0.97-1.20)$ & 0.164 & $1.04(0.93-1.17)$ & 0.541 \\
\hline Anaesthesia type & $1.15(0.97-1.35)$ & 0.100 & $1.13(0.95-1.34)$ & 0.177 \\
\hline Vaginal hysterectomy & $1.03(0.92-1.15)$ & 0.656 & $0.80(0.63-1.01)$ & 0.064 \\
\hline Uterosacral suspension & $1.20(1.09-1.33)$ & $<0.0001$ & $1.06(0.78-1.44)$ & 0.697 \\
\hline Sacrospinous suspension & $1.07(0.98-1.18)$ & 0.139 & $0.94(0.80-1.09)$ & 0.400 \\
\hline Laparoscopic sacrocolpopexy & $0.86(0.73-1.00)$ & 0.052 & $0.93(0.77-1.12)$ & 0.448 \\
\hline Obliterative & $0.87(0.70-1.08)$ & 0.199 & $0.94(0.73-1.22)$ & 0.641 \\
\hline Vaginal hysterectomy and uterosacral suspension & $1.21(1.09-1.35)$ & $<0.0001$ & $1.29(0.90-1.86)$ & 0.169 \\
\hline Vaginal hysterectomy and sacrospinous suspension & $1.28(1.14-1.44)$ & $<0.0001$ & $1.53(1.18-1.97)$ & 0.001 \\
\hline Bladder protocol & $1.02(0.93-1.12)$ & 0.663 & $0.95(0.86-1.05)$ & 0.284 \\
\hline
\end{tabular}

Items in bold indicate significance at the $p<0.05$ level

Table 5 Results of ordinal regression analysis examining the association between clinical variables and ordered void class

\begin{tabular}{|c|c|c|c|c|}
\hline Clinical variables & Crude odds ratio (OR, $95 \% \mathrm{Cl}$ ) & $p$ value & $\begin{array}{l}\text { Adjusted odds ratio (OR, } \\
95 \% \mathrm{Cl})\end{array}$ & $p$ value \\
\hline Age & $1.00(0.98-1.01)$ & 0.726 & $1.00(0.98-1.01)$ & 0.717 \\
\hline BMI & $0.98(0.95-1.01)$ & 0.203 & $0.97(0.94-1.00)$ & 0.047 \\
\hline MUS & $2.21(1.53-3.19)$ & $<0.0001$ & $2.27(1.52-3.40)$ & $<0.0001$ \\
\hline ASA score & $1.19(0.85-1.65)$ & 0.314 & $1.47(1.01-2.14)$ & 0.046 \\
\hline Anterior REPAIR & $1.58(1.13-2.22)$ & 0.008 & $1.47(0.96-2.25)$ & 0.074 \\
\hline Posterior repair & $0.93(0.65-1.34)$ & 0.707 & $0.71(0.48-1.06)$ & 0.091 \\
\hline Vaginal hysterectomy & $2.13(1.53-2.96)$ & $<0.0001$ & $1.17(0.59-2.33)$ & 0.6466 \\
\hline Uterosacral suspension & $1.75(1.22-2.52)$ & 0.002 & $1.53(0.83-2.82)$ & 0.170 \\
\hline Sacrospinous suspension & $1.33(0.95-1.86)$ & 0.092 & $0.90(0.50-1.60)$ & 0.715 \\
\hline Laparoscopic sacrocolpopexy & $0.69(0.40-1.21)$ & 0.196 & $1.02(0.51-2.04)$ & 0.952 \\
\hline Obliterative & $0.75(0.35-1.58)$ & 0.445 & $1.57(0.61-4.00)$ & 0.347 \\
\hline $\begin{array}{l}\text { Vaginal hysterectomy and sacrospinous } \\
\text { suspension }\end{array}$ & $2.34(1.58-3.47)$ & $<0.0001$ & $2.18(0.96-4.96)$ & 0.062 \\
\hline Bladder protocol & $1.26(0.90-1.76)$ & 0.175 & $1.01(0.70-1.46)$ & 0.942 \\
\hline
\end{tabular}

${ }^{*}$ Crude ORs calculated using the outcome of void class

Items in bold indicate significance at the $p<0.05$ level

Strengths of our study include the large sample size $(\mathrm{n}=992)$ and the level of peri-operative details available. The number and details of the voiding trials were accessed on the electronic surgical patient chart, which allowed a detailed analysis of the number of TOV and voiding parameters used. Limitations include not being able to account for intraoperative fluid administration in our model, as it has been suggested that volumes $\geq 750 \mathrm{ml}$ increase risk of
POUR $[13,14]$. However, our centre adheres to ERAS principles including judicious use of peri-operative IV fluids and TOV did not start until post-operative day 1 meaning most intra-operative IV fluid would have been dealt with by diuresis overnight. While women with pre-existing PVR $>150 \mathrm{ml}$ were not included in this cohort, information regarding other voiding parameters such as speed of urinary stream and shape of Uroflowmetry curve were 
not included to assess their value as predictive factors. A further limitation is that our results are not generalizable to patients being discharged on the day of surgery, where a higher number of patients have been shown to fail the voiding protocol and require catheterization [27]. Finally, it is possible that our sample size was underpowered to detect differences in some of the measured variables (e.g., differences between surgery types).

\section{Conclusion}

POUR is common after pelvic floor surgery. A handful of POUR risk factors have been identified by our study, including MUS placement and concomitant hysterectomy with sacrospinous vault suspension. However, POUR still occurs in women without these risk factors making it difficult to predict pre-operatively. Normalization of PVR usually takes two voids, but a third void may be required. In women who are at higher risk of POUR and where day surgery is planned, surgeons should consider placing them at the start of the operative list to allow for time to void postoperatively. Women should be counselled regarding high rates of POUR in advance of surgery to allow them to manage postoperative expectations.

\section{Acknowledgements}

The members for for the Calgary Women's Pelvic Health Research Group: Erin A. Brennand, Shunaha Kim-Fine, Magali Robert, Colin Birch, Magnus Murphy, Kaylee Ramage, Emily Sandwith.

\section{Authors' contributions}

BA: Project development and editing of manuscript, KR: Project development, statistical analysis and editing of manuscript, ES: Data entry, project development, and editing of manuscript, EB: Project development, statistical analysis, data entry and editing of manuscript. All authors read and approve the final manuscript.

\section{Funding}

Not applicable.

\section{Availability of data and materials}

The datasets used and/or analysed during the current study available from the corresponding author on reasonable request.

\section{Declarations}

\section{Ethics approval and consent to participate}

This project was reviewed and approved by the Foothills Medical Centre Research Ethics Boards (IDs\# CHREB150706). All methods were carried out in accordance with relevant guidelines and regulations. As this was a retrospective review individual informed consent from each individual was not deemed necessary by the Foothills Medical Centre Research Ethics Boards.

\section{Consent for publication}

The authors give consent for publication.

\section{Competing interests}

The authors declare that they have no conflict of interest.

Received: 28 December 2020 Accepted: 23 April 2021

Published online: 11 May 2021

\section{References}

1. Foster R, Borawski K, South M, Weidner A, Webster G, Amundsen C. A randomized, controlled trial evaluating 2 techniques of postoperative bladder testing after transvaginal surgery. Am J Obstet Gynecol Gynecol. 2007;197(6):627.e1-4

2. Geller E, Hankins K, Parnell B, Robinson B, Dunivan G. A randomized, controlled trial evaluating 2 techniques of postoperative bladder testing after transvaginal surgery. Obstet Gynecol. 2007;118(3):637-42.

3. Roovers R, Hakvoort M, Dijkgraaf M, Burger M, Emanuel J. Predicting short-term urinary retention after vaginal prolapse surgery. Neurourol Urodyn. 2009;28(3):225-8.

4. Geller E. Prevention and management of postoperative urinary retention after urogynecologic surgery. Int J Womens Heal. 2014;6:829-38.

5. Bross S, Schumacher S, Scheepe J, Zendler S, Braun P, Alken P, et al. Effects of acute urinary bladder overdistension on bladder response during sacral neurostimulation. Eur Urol. 1999:36(4):354-9.

6. Madersbacher H, Cardozo L, Chapple C, Abrams P, Toozs-Hobson P, Young $J$, et al. What are the causes and consequences of bladder overdistension? ICI-RS 2011. Neurourol Urodyn. 2012;31:317-21.

7. Ferrante K, Kim H, Brubaker L, Wai C, Norton P, Kraus S, et al. Repeat post-op voiding trials: an inconvenient correlate with success. Neurourol Urodyn. 2014;33(8):1225-8.

8. Dietz $\mathrm{H}$, Haylen B, Vancaillie T. Female pelvic organ prolapse and voiding function. Int Urogynecol J. 2002;13(5):284-8.

9. Hong B, Park S, Kim H, Choo M. Factors predictive of urinary retention after a tension-free vaginal tape procedure for female stress urinary incontinence. J Urol. 2003;170(3):852-6.

10. Sokol A, Jelovsek J, Walters M, Paraiso M, Barber M. Incidence and predictors of prolonged urinary retention after TVT with and without concurrent prolapse surgery. Am J Obstet Gynecol. 2005;192(5 SPEC. ISS):1537-43.

11. Kobak W, Walters M, Piedmonte M. Determinants of voiding after three types of incontinence surgery: a multivariable analysis. Obstet Gynecol. 2001;97(1):86-91.

12. Wang R, Won S, Haviland M, von Bargen E, Hacker M, Li J, et al. Voiding trial outcome following pelvic floor repair without incontinence procedures. Int Urogynecol J. 2016;27(8):1215-20.

13. Keita H, Diouf E, Tubach F, Brouwer T, Dahmani S, Mantz J, et al. Predictive factors of early postoperative urinary retention in the postanesthesia care unit. Anesth Analg. 2005;101(2):592-6.

14. Toyonaga T, Matsushima M, Sogawa N, Jiang S, Matsumura N, Shimojima $Y$, et al. Postoperative urinary retention after surgery for benign anorectal disease: potential risk factors and strategy for prevention. Int J Colorectal Dis. 2006;21(7):676-82.

15. Bracken J, Huffaker $K$, Yandell P, Handcock T, Higgins E, Kuehl T, et al. A randomized comparison of bupivacaine versus saline during placement of tension-free vaginal tape. Female Pelvic Med Reconstr Surg. 2012;18(2):93-6.

16. Geller G, Kelly H, Parnell B, Robinson B, Dunivan G. Diagnostic accuracy of retrograde and spontaneous voiding trials for postoperative voiding dysfunction: a randomized controlled trial. Obstet Gynecol. 2011;118(3):637-42.

17. Pulvino J, Duecy E, Buchsbaum G, Flynn M. Comparison of 2 techniques to predict voiding efficiency after inpatient urogynecologic surgery. J Urol. 2010;184(4):1408-12.

18. Dolgun N, Jones K, Harmanli O (2020) Voided volume for postoperative voiding assessment following prolapse and urinary incontinence surgery. Int Urogynecol J. 2020;

19. Odom BD, Ehlert M, Gupta P, Cholyway R, Boura JA, Killinger KA, et al. Clinical comparison of 2 trial-of-void methods after outpatient midurethral sling placement. Female Pelvic Med Reconstr Surg. 2016;22(3):172-4.

20. Saaby ML, Lose G. Repeatability of post-void residual urine $\geq 100 \mathrm{ml}$ in urogynaecologic patients. Int Urogynecol J. 2012;23(2):207-9.

21. Dunsmuir WD, Feneley M, Corry DA, Bryan J, Kirby RS. The day-to-day variation (test-retest reliability) of residual urine measurement. Br J Urol. 1996;77(2):192-3.

22. Schachar JS, Ossin D, Plair AR, Hurtado EA, Parker-Autry C, Badlani G, et al. Optimal timing of a second postoperative voiding trial in women with incomplete bladder emptying after vaginal reconstructive surgery: a randomized trial. Am J Obstet Gynecol. 2020;223(2):260.e1-260.e9. 
23. Kondo W, Corrêa Leite GK, Fernandes R, Kamergorodsky G, Fin FR, Cordeiro Fernandes LF et al. Useful pelvic retroperitoneal neuroanatomy for benign gynecologic surgery: a cadaveric dissection. J Minim Invasive Gynecol 2020;22:S1553-4650(20)30245-4.

24. van der Ploeg JM, van der Steen A, Oude Rengerink K, van der Vaart CH, Roovers JP. Prolapse surgery with or without stress incontinence surgery for pelvic organ prolapse: a systematic review and meta-analysis of randomised trials. BJOG. 2014;121(5):537-47.

25. Bisch S, Wells T, Gramlich L, Faris P, Wang X, Tran D, et al. Enhanced Recovery After Surgery (ERAS) in gynecologic oncology: system-wide implementation and audit leads to improved value and patient outcomes. Gynecol Oncol Gynecol Oncol. 2018;151(1):117-23.
26. Elkadry EA, Kenton KS, FitzGerald MP, Shott S, Brubaker L. Patient-selected goals: a new perspective on surgical outcome. Am J Obstet Gynecol. 2003;189:1551-8.

27. Carter-Brooks CM, Zyczynski HM, Moalli PA, Brodeur PG, Shepherd JP. Early catheter removal after pelvic floor reconstructive surgery: a randomized trial. Int Urogynecol J. 2018;29:1203-12.

\section{Publisher's Note}

Springer Nature remains neutral with regard to jurisdictional claims in published maps and institutional affiliations.
Ready to submit your research? Choose BMC and benefit from:

- fast, convenient online submission

- thorough peer review by experienced researchers in your field

- rapid publication on acceptance

- support for research data, including large and complex data types

- gold Open Access which fosters wider collaboration and increased citations

- maximum visibility for your research: over $100 \mathrm{M}$ website views per year

At BMC, research is always in progress.

Learn more biomedcentral.com/submissions 